\title{
Aortic and innominate routes for transcatheter aortic valve implantation
}

\author{
Jean Porterie, $\mathrm{MD},{ }^{\mathrm{a}}$ Nicolas Mayeur, $\mathrm{MD}, \mathrm{PhD},{ }^{\mathrm{b}}$ Thibaut Lhermusier, $\mathrm{MD}, \mathrm{PhD},{ }^{\mathrm{c}}$ Nicolas Dumonteil, $\mathrm{MD},{ }^{\mathrm{c}}$
} Thomas Chollet, MD,${ }^{\mathrm{c}}$ Olivier Lairez, $\mathrm{MD}, \mathrm{PhD},{ }^{\mathrm{c}}$ and Bertrand Marcheix, $\mathrm{MD}, \mathrm{PhD}^{\mathrm{a}}$

\section{ABSTRACT}

Objectives: This study aimed at evaluating the efficacy and safety of the transaortic approach for the transcatheter aortic valve implantation procedure using balloon-expandable and self-expanding devices.

Methods: From January 2012 to December 2016, the transaortic-transcatheter aortic valve implantation procedure was performed in 206 consecutive patients at the Rangueil University Hospital. All procedures were performed by a multidisciplinary heart team. The ascending aorta $(27 \%)$ or innominate artery $(73 \%)$ was exposed through a J-type manubriotomy. Events were adjudicated according to Valve Academic Research Consortium-2 criteria.

Results: Mean age and logistic European System for Cardiac Risk Evaluation II were $83.9 \pm 6.7$ years and $16.8 \% \pm 10.8 \%$, respectively. Balloon-expandable and self-expanding valves were implanted in $59.7 \%$ and $40.3 \%$ of patients, respectively. Device success rate was $98.1 \%$. Thirty-day overall mortality, cardiovascular mortality, cerebrovascular event, myocardial infarction, and permanent pacemaker implantation rates were $5.3 \%, 4.4 \%, 1.5 \%, 1.0 \%$, and $9.7 \%$, respectively (1-year rates: $15.5 \%, 9.2 \%, 3.9 \%, 3.4 \%$, and $10.2 \%$, respectively). Life-threatening bleeding and major vascular complications $(7.3 \%$ and $3.9 \%$, respectively) were not related to the central access site in approximately half of the cases. Multivariable Cox regression analysis identified preoperative renal failure as an independent predictor of overall mortality (odds ratio, 2.82; $95 \%$ confidence interval, 1.73-4.59; $P<.0001)$. At the 1-year follow-up, most patients had experienced improved functional status and $98.4 \%$ of them were free of moderate to severe paravalvular leak.

Conclusions: In a higher-risk subgroup within the patient population receiving transcatheter aortic valve implantation, transaortic-transcatheter aortic valve implantation was successfully performed in $98.1 \%$ of cases, with high functional improvement and low rates of mortality and adverse events, especially neurologic complications. (J Thorac Cardiovasc Surg 2019;157:1393-401)

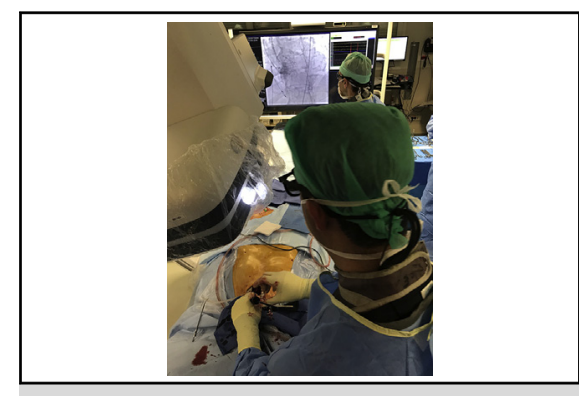

After TAo-TAVI, 30-day mortality and stroke rates were $5.3 \%$ and $1.0 \%$, respectively.

\section{Central Message}

In a higher-risk subgroup within the TAVI population, the TAo technique was efficient and safe, with low rates of mortality and adverse events, especially neurologic complications.

\section{Perspective}

The validity of a TAVI program is conditioned by the control of different available approaches to select the best strategy for the patient, achieve optimal results, and avoid complications. By its safety and efficacy even in very high-risk patients, the TAo technique is an essential tool for a heart team and could represent a first-choice strategy.

See Commentaries on pages 1402 and 1404.
The transcatheter aortic valve implantation (TAVI) procedure has been developed as an alternative option to treat severe aortic stenosis (AS) in patients with a contraindication or high surgical risk for conventional aortic valve

\footnotetext{
From the Departments of ${ }^{\mathrm{a} C a r d i o v a s c u l a r}$ Surgery, ${ }^{\mathrm{b}}$ Anesthesiology, and ${ }^{\mathrm{c}}$ Cardiology, Rangueil University Hospital, Toulouse, France.

Institutional Review Board Approval: National Commission on Informatics and Liberty $\mathrm{n}^{\circ} 2171001(04-2018)$.

Received for publication Jan 6, 2018; revisions received June 25, 2018; accepted for publication July 8, 2018; available ahead of print Sept 27, 2018.

Address for reprints: Jean Porterie, MD, Department of Cardiovascular Surgery, Rangueil University Hospital, Toulouse, France, 1, Ave Jean Poulhès, Toulouse Cedex TSA 50032 - 31059, France (E-mail: porterie.j@chu-toulouse.fr). $0022-5223 / \$ 36.00$

Copyright (c) 2018 by The American Association for Thoracic Surgery https://doi.org/10.1016/j.jtcvs.2018.07.098
}

replacement (AVR). ${ }^{1-3}$ The procedure can be performed through the femoral artery, ${ }^{1}$ the subclavian (SC) artery, ${ }^{4}$ the carotid artery, ${ }^{5-7}$ or a transapical (TA) approach. ${ }^{8}$ Despite downsizing of the delivery systems, the transfemoral (TF) route is contraindicated in patients with excessive atherosclerosis, calcifications, or tortuosity of iliofemoral arteries. ${ }^{9}$ The first described alternative route

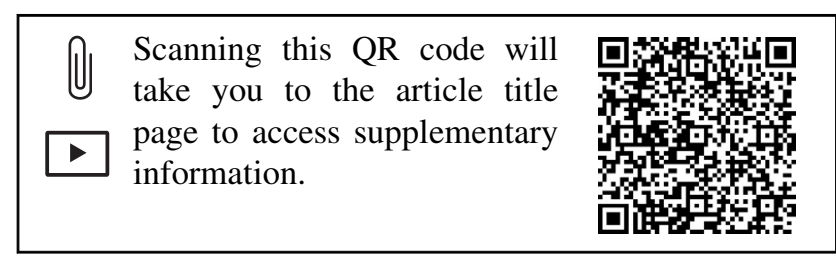




$\begin{array}{ll}\text { Abbreviations and Acronyms } \\ \text { AA } & =\text { ascending aorta } \\ \text { AKI } & =\text { acute kidney injury } \\ \text { AS } & =\text { aortic stenosis } \\ \text { AVR } & =\text { aortic valve replacement } \\ \text { euroSCORE } & =\text { European System for Cardiac Risk } \\ & \text { Evaluation } \\ \text { IA } & =\text { innominate artery } \\ \text { ICU } & =\text { intensive care unit } \\ \text { MI } & =\text { myocardial infarction } \\ \text { PAD } & =\text { peripheral artery disease } \\ \text { PPM } & =\text { permanent pacemaker } \\ \text { PRBC } & =\text { packed red blood cells } \\ \text { PVL } & =\text { paravalvular leak } \\ \text { SC } & =\text { subclavian } \\ \text { TA } & =\text { transapical } \\ \text { TAo } & =\text { transaortic } \\ \text { TAVI } & =\text { transcatheter aortic valve } \\ & \text { implantation } \\ \text { TC } & =\text { transcarotid } \\ \text { TF } & =\text { transfemoral }\end{array}$

was the TA approach. It has been identified to be associated with reduced survival, potential negative impact on respiratory function, myocardial damage, bleeding, and injuries of the mitral subvalvular apparatus. ${ }^{10-14}$ The transaortic (TAo) route emerged as an alternative technique to avoid or decrease these difficulties and complications. Moreover, the potential advantages of this approach are ease of access, good visualization of aortic valve, and excellent control of prosthesis positioning, as well as reduction of vascular and bleeding complications or cerebrovascular events by avoiding navigation in the aortic arch. ${ }^{15-21}$ All of these elements may improve postoperative recovery in this elderly population. The aim of our study was to evaluate the safety and efficacy of the TAo-TAVI in a large population.

\section{MATERIALS AND METHODS}

From January 2012 to December 2016, a total of 1039 consecutive patients underwent TAVI procedure in our institution. The decision to perform a TAVI procedure was discussed by a multidisciplinary heart team. TAVI was considered for patients with severe symptomatic AS and contraindication for conventional AVR or high surgical risk defined as logistic European System for Cardiac Risk Evaluation (euroSCORE) 20\% or greater, Society of Thoracic Surgeons Predicted Risk of Mortality score $10 \%$ or greater, or the presence of significant comorbidities not captured by the scoring systems (eg, frailty, porcelain aorta, cirrhosis). The frailest patients, whose life expectancy was less than 1 year, were medically treated. All patients selected for TAVI underwent a standardized screening, including a physical examination, an echocardiography, a coronary angiography, a chest and aorto-ilio-femoral computed tomography scan, and an evaluation of pulmonary and renal functions. Alternative approaches to TF route were considered in case of unsuitable iliofemoral access (small size, excessive tortuosity, or calcifications). On the basis of the results of these investigations, patients were selected to undergo TAVI by different approaches: TF-TAVI was performed in 796 patients $(76.6 \%)$, TAoTAVI was performed in 206 patients $(19.8 \%)$, and TA- and SC-TAVI were performed in 24 patients $(2.3 \%)$ and 13 patients $(1.3 \%)$, respectively (Figure 1). After providing written informed consent, they were included in our TAVI database, recording full cardiac history, comorbidities, procedural, 30-day, and 1-year outcomes.

All the procedures were performed in a hybrid operating room by a team composed of interventional cardiologists, cardiac surgeons, and cardiac anesthesiologists, as described previously. ${ }^{17}$ The step-by-step description of the procedure is reported (Table E1 and Video 1). All patients underwent a J-shaped manubriotomy down to the second right intercostal space. A safe entry site was exposed on the distal ascending aorta (AA) after the opening of the pericardium in the first 35 patients. In the following 21 patients, the extra pericardial aorta was punctured without a pericardial opening. Finally, in the last 150 patients, the access point was shifted to the innominate artery (IA).

The procedures were performed with the 2 devices commercially available in France: the balloon-expandable SAPIEN XT valve (Edwards Lifesciences, Irvine, Calif) from January 2012 to September 2014, the SAPIEN 3 prosthesis (Edwards Lifesciences) from September 2014 to December 2016, or the self-expanding CoreValve Revalving system (Medtronic Inc, Minneapolis, Minn). The choice of TAVI device was at the discretion of the heart team in full knowledge of the medical history (ie, previous conduction disturbances, valve-in-valve procedure) and the anatomic features assessed by noninvasive and invasive imaging (ie, annulus diameter and aortic root dimensions, calcifications, bicuspid valve).

All patients were monitored in the intensive care unit (ICU) for at least 24 hours. After discharge from the hospital, they underwent long-term follow-up, with a checkup at 30 days, 6 months, 1 year, and annually thereafter. The outcomes of this study were evaluated according to Valve Academic Research Consortium-2 criteria. ${ }^{22}$ Primary end points were 30 -day, 1 -year, and overall mortality rates. Secondary end points were 30 -day and 1 -year complications rates.

\section{Statistical Analysis}

Statistical analysis was performed using Xlstat (Addinsoft, v2016). Categoric variables are presented as absolute numbers and percentages. Continuous variables are presented as means \pm standard deviations. We compared categoric variables with the chi-square test and Fisher exact test, and continuous variables with the Student $t$ test. We tested continuous variables for normality with several statistical tests, including the ShapiroWilk test. Only preoperative mean gradients had a normal distribution and were tested with the $t$ test. We used the Cox regression proportional hazards model for multivariable analysis. We assessed time-to-event variables with Kaplan-Meier estimates based on all available data and compared them with the log-rank test. Changes in aortic valve mean gradient and area were assessed using analysis of variance with Kruskal-Wallis test.

\section{RESULTS}

A total of 206 patients underwent TAo-TAVI procedure during the study period. Mean age was $83.9 \pm 6.7$ years, and $58.3 \%$ were female (Table 1 ). The mean left ventricular ejection fraction was $52.7 \% \pm 14.4 \%$. A high proportion of patients $(63.1 \%)$ had coronary artery disease, and 25 patients $(12.1 \%)$ underwent a redo procedure, including 5 cases of valve-in-valve. Among other significant comorbidities, $15 \%$ of patients had previous cerebrovascular disease and $64.1 \%$ of patients had peripheral artery disease (PAD). Mean logistic euroSCORE II and Society of Thoracic 


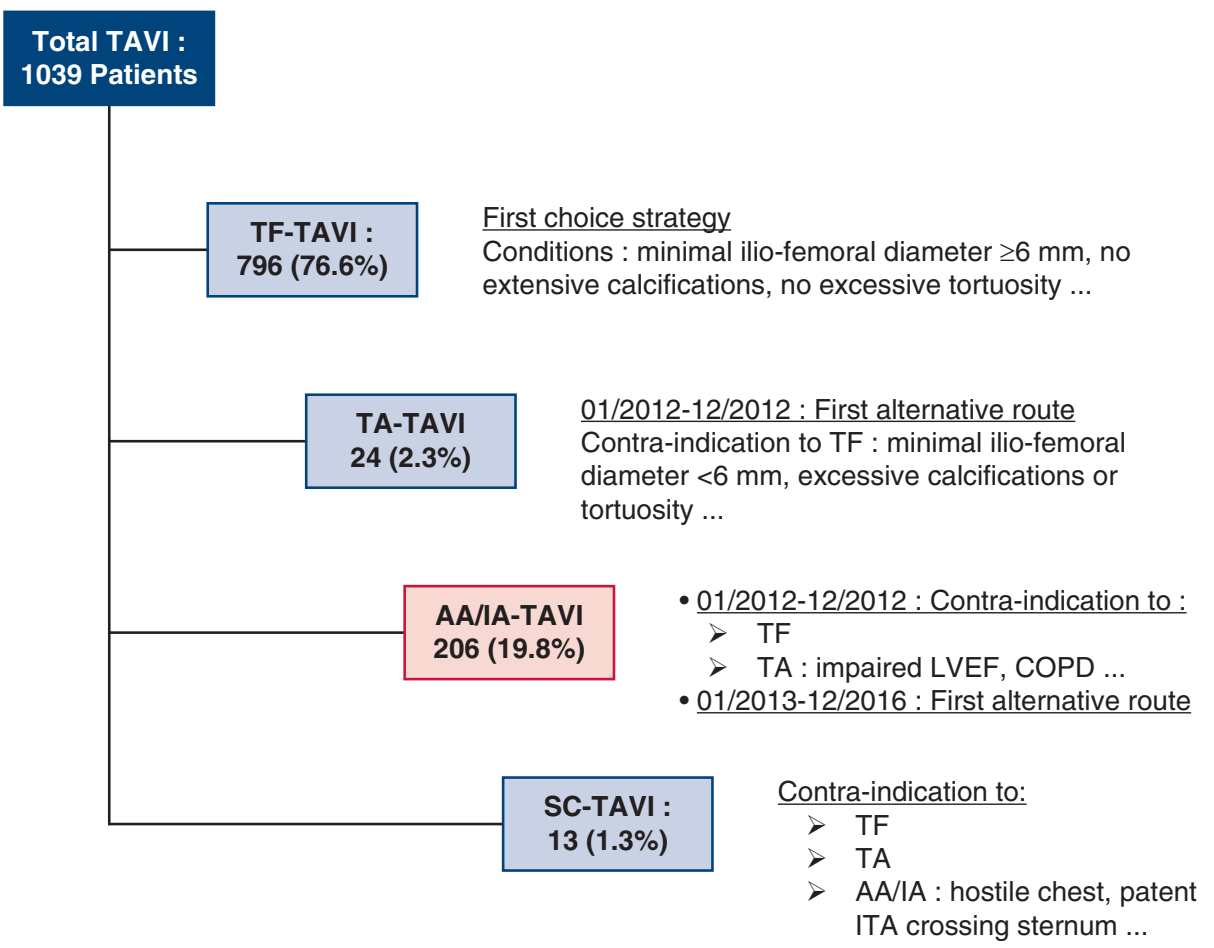

FIGURE 1. Institutional TAVR volume and access route strategies. TAVI, Transcatheter aortic valve implantation; $T F$, transfemoral; $T A$, transapical; $A A$, ascending aorta; $I A$, innominate artery access; $L V E F$, left ventricular ejection fraction; $C O P D$, chronic obstructive pulmonary disease; ITA, internal thoracic artery; $S C$, subclavian.

Surgeons Predicted Risk of Mortality score were $16.8 \% \pm 10.8 \%$ and $8.9 \% \pm 5.4 \%$, respectively.

The procedure was performed through the AA or IA in $27.2 \%$ and $72.8 \%$ of patients, respectively (Table 2). Comparative data of the AA and IA groups regarding baseline characteristics and procedural, 30-day, and 1-year outcomes are shown in Tables E2 to E5. The mean procedural time, fluoroscopic time, and amount of contrast media use were $50.6 \pm 12.3$ minutes, $11.6 \pm 3.8$ minutes, and $117.3 \pm 40.5 \mathrm{~mL}$, respectively, with significantly lower values in the IA group than in the AA group. The SAPIEN XT valve was implanted in $27.2 \%$ of patients, the SAPIEN 3 was implanted in $32.5 \%$ of patients, the CoreValve (Medtronic) was implanted in $35.4 \%$ of patients, and the EvolutR (Medtronic) was implanted in $4.9 \%$ of patients. The procedural success rate was $98.1 \%$, and there were 3 intraoperative deaths $(1.5 \%)$, relative to left main coronary occlusion in 2 patients and acute aortic dissection in 1 patient. We observed 2 other cases of left main obstruction that was successfully treated by stenting. Implantation of a second prosthesis was required in 1 patient because of device deployment at a lower level than desired.

Before intervention, $70.4 \%$ of patients were classified with New York Heart Association functional class III and

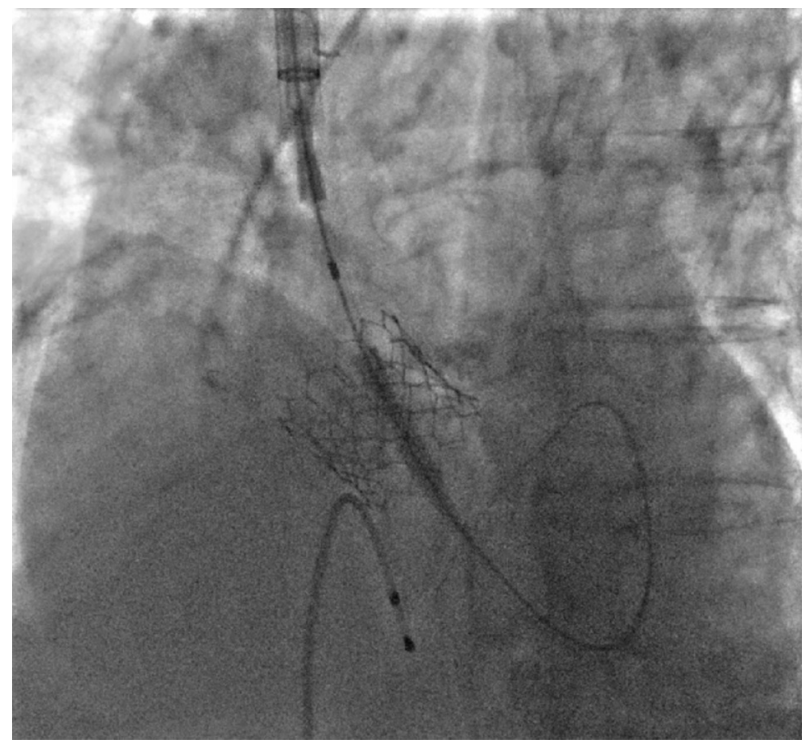

VIDEO 1. All the procedures were performed in a hybrid operating room by a multidisciplinary team composed of interventional cardiologists, cardiac surgeons, and cardiac anesthesiologists. All patients underwent a $\mathrm{J}$-shaped manubriotomy down to the second right intercostal space. A safe entry site was exposed on the IA in most patients. The procedures were performed with a balloon-expandable or self-expanding prosthesis. Video available at: https://www.jtcvs.org/article/S0022-5223(18)32278-5/fulltext. 
TABLE 1. Baseline characteristics

\begin{tabular}{|c|c|}
\hline & Overall $(n=206)$ \\
\hline Age (y) & $83.9 \pm 6.7$ \\
\hline Female gender & $120(58.3)$ \\
\hline Diabetes mellitus & $65(31.6)$ \\
\hline \multicolumn{2}{|l|}{ NYHA class } \\
\hline I-II & $61(29.6)$ \\
\hline III-IV & $145(70.4)$ \\
\hline Pulmonary edema & $103(50.0)$ \\
\hline Angina pectoris CCS class III-IV & $42(20.4)$ \\
\hline Prior relative hospitalization & $150(72.8)$ \\
\hline \multicolumn{2}{|l|}{ Cardiac comorbidity } \\
\hline Coronary artery disease & $130(63.1)$ \\
\hline Previous MI & $31(15.0)$ \\
\hline Previous PCI & $95(46.1)$ \\
\hline Previous $\mathrm{CABG}$ & $20(9.7)$ \\
\hline Previous AVR & $5(2.4)$ \\
\hline Other previous cardiac surgery & $3(1.5)$ \\
\hline Atrial fibrillation & $64(31.1)$ \\
\hline Previous pacemaker implantation & $29(14.1)$ \\
\hline \multicolumn{2}{|l|}{ Extracardiac comorbidity } \\
\hline Cerebrovascular disease & $31(15.0)$ \\
\hline PAD & $132(64.1)$ \\
\hline Severe COPD & $80(38.8)$ \\
\hline Renal failure (eGFR <35 mL/min) & $47(22.8)$ \\
\hline Liver cirrhosis & $2(0.9)$ \\
\hline \multicolumn{2}{|l|}{ Surgical risk } \\
\hline Logistic euroSCORE II (\%) & $16.8 \pm 10.8$ \\
\hline STS PROM score $(\%)$ & $8.9 \pm 5.4$ \\
\hline \multicolumn{2}{|l|}{ Unfavorable anatomic features } \\
\hline Porcelain aorta & $8(3.9)$ \\
\hline Mediastinal radiation therapy & $14(6.8)$ \\
\hline ITA or other conduit crossing midline & $18(8.7)$ \\
\hline \multicolumn{2}{|l|}{ Imaging } \\
\hline Indexed EOA $\left(\mathrm{cm}^{2} / \mathrm{m}^{2}\right)$ & $0.44 \pm 0.14$ \\
\hline $\mathrm{AV}$ mean gradient $(\mathrm{mm} \mathrm{Hg})$ & $44.3 \pm 14.8$ \\
\hline $\operatorname{LVEF}(\%)$ & $52.7 \pm 14.4$ \\
\hline Moderate or severe MR & $5 / 190(2.6)$ \\
\hline Previous aortic valvuloplasty & $71(34.5)$ \\
\hline
\end{tabular}

Values are expressed as mean \pm standard deviation (SD) or $\mathrm{n}(\%) . N Y H A$, New York Heart Association; CCS, Canadian Cardiovascular Society; MI, myocardial infarction; $P C I$, percutaneous coronary intervention; $C A B G$, coronary artery bypass grafting; $A V R$, aortic valve replacement; $P A D$, peripheral artery disease; $C O P D$, chronic obstructive pulmonary disease; $e G F R$, estimated glomerular filtration rate; euroSCORE, European System for Cardiac Risk Evaluation; STS PROM, Society of Thoracic Surgeons Predicted Risk of Mortality; ITA, internal thoracic artery; EOA, effective orifice area; $A V$, aortic valve; $L V E F$, left ventricular ejection fraction; $M R$, mitral regurgitation.

IV, postoperatively decreasing to $5.7 \%$ and $5.4 \%$ at 6 months and 1 year, respectively $(P<.0001$; Figure E1). At discharge, control echocardiography reported a mean postoperative indexed effective orifice area of $1.06 \pm 0.21 \mathrm{~cm}^{2} / \mathrm{m}^{2}$ to compare with $0.44 \pm 0.14 \mathrm{~cm}^{2} / \mathrm{m}^{2}$ before the procedure $(P<.0001)$. Likewise, the aortic valve $(\mathrm{AV})$ mean gradient decreased from $44.3 \pm 14.8 \mathrm{~mm} \mathrm{Hg}$ to
TABLE 2. Procedural outcomes

\begin{tabular}{lc}
\hline & Overall $(\mathbf{n}=\mathbf{2 0 6})$ \\
\hline Access & \\
Aortic route & $56(27.2)$ \\
Innominate route & $150(72.8)$ \\
Procedural time (min) & $50.6 \pm 12.3$ \\
Fluoroscopy time (min) & $11.6 \pm 3.8$ \\
Contrast media used (mL) & $117.3 \pm 40.5$ \\
Valve implanted & \\
SAPIEN XT (Edwards Lifesciences, & $56(27.2)$ \\
$\quad$ Irvine, Calif) & \\
SAPIEN 3 (Edwards Lifesciences) & $67(32.5)$ \\
CoreValve (Medtronic Inc, Minneapolis, & $73(35.4)$ \\
$\quad$ Minn) & \\
EvolutR (Medtronic Inc) & $10(4.9)$ \\
Valve size (mm) & \\
23 & $51(24.8)$ \\
26 & $86(41.7)$ \\
V29 & $69(33.5)$ \\
VARC-2 procedural success & $202(98.1)$ \\
Second valve & $1(0.5)$ \\
Coronary obstruction & $4(1.9)$ \\
Conversion to surgery & $0(0.0)$ \\
Periprocedural death & $3(1.5)$ \\
PVL & \\
Mild & $13(6.3)$ \\
Moderate to severe & $0(0.0)$ \\
Transfusions & \\
PRBC use & $75(36.4)$ \\
PRBC units transfused & $2.6 \pm 1.0$ \\
Platelet units transfused & $6(2.9)$ \\
\hline
\end{tabular}

Values are expressed as mean \pm SD or $\mathrm{n}(\%)$. VARC-2, Valve Academic Research Consortium-2; $P V L$, paravalvular leak; $P R B C$, packed red blood cells.

$10.5 \pm 3.2 \mathrm{~mm} \mathrm{Hg}(P<.0001)$. These results remained stable at the 1-year follow-up (Figure E2). The 30-day and 1 -year rates of moderate paravalvular leak (PVL) were $0 \%$ and $1.6 \%$, respectively, with no case of severe leak (Tables 3 and 4).

Mean ICU and hospital stays were $2.5 \pm 1.7$ days and $8.1 \pm 2.6$ days, respectively, and patients in the IA group experienced significantly shorter stays $(P<.0001)$. Thirty-day overall and cardiovascular mortality rates were $5.3 \%$ and $4.4 \%$, respectively (Tables 3 and 5 ). The myocardial infarction (MI) rate was $1.0 \%$ (2 intraprocedural deaths). Two patients experienced a stroke $(1.0 \%)$, and 1 case of transient ischemic attack was observed $(0.5 \%)$. Life-threatening bleeding complications occurred in $7.3 \%$ of patients ( 4 cases not related to the aortic access: 2 cases of right ventricle wound due to pacing wire and leading to tamponade, 1 case related to a major vascular complication on the femoral artery, hemorrhage related to Heyde's syndrome in 1 patient) and were significantly less frequent in the IA group $(4.7 \%$ vs $14.3 \%, P=.03)$. Major vascular 
TABLE 3. Thirty-day outcomes

\begin{tabular}{|c|c|}
\hline & Overall $(n=206)$ \\
\hline ICU stay (d) & $2.5 \pm 1.7$ \\
\hline Hospital stay (d) & $8.1 \pm 2.6$ \\
\hline Overall mortality & $11(5.3)$ \\
\hline CV mortality & $9(4.4)$ \\
\hline MI & $2(1.0)$ \\
\hline Cerebrovascular event & $3(1.5)$ \\
\hline Stroke & $2(1.0)$ \\
\hline TIA & $1(0.5)$ \\
\hline MACCE (death/MI/stroke) & $13(6.3)$ \\
\hline Life-threatening bleeding & $15(7.3)$ \\
\hline Major vascular complication & $8(3.9)$ \\
\hline AKI (stage 2 or 3 ) & $5(2.4)$ \\
\hline New PPM implantation & $20(9.7)$ \\
\hline \multicolumn{2}{|l|}{ Imaging } \\
\hline Indexed EOA $\left(\mathrm{cm}^{2} / \mathrm{m}^{2}\right)$ & $1.06 \pm 0.21$ \\
\hline AV mean gradient $(\mathrm{mm} \mathrm{Hg})$ & $10.5 \pm 3.2$ \\
\hline Mild PVL & $12 / 200(6.0)$ \\
\hline Moderate to severe PVL & $0(0.0)$ \\
\hline $\operatorname{LVEF}(\%)$ & $52.5 \pm 9.7$ \\
\hline Valve-related dysfunction & $0(0.0)$ \\
\hline \multicolumn{2}{|c|}{$\begin{array}{l}\text { Values are expressed as mean } \pm \mathrm{SD} \text { or n }(\%) . I C U \text {, Intensive care unit; } C V \text {, } \\
\text { cardiovascular; } M I \text {, myocardial infarction; } T I A \text {, transient ischemic attack; } M A C C E \text {, } \\
\text { major adverse cardiac and cerebrovascular events; } A K I \text {, acute kidney injury (accord- } \\
\text { ing to the AKI Network criteria); } P P M \text {, permanent pacemaker; } E O A \text {, effective } \\
\text { orifice area; } A V \text {, aortic valve; } P V L \text {, paravalvular leak; } L V E F \text {, left ventricular ejection } \\
\text { fraction. }\end{array}$} \\
\hline
\end{tabular}

complications $(3.9 \%)$ were related to the aortic access site in 4 patients ( 4 other cases were related to the femoral puncture for pigtail insertion, leading to ipsilateral lower limb ischemia and treated by ilio-femoral bypass in 2 cases, embolectomy in 1 case, and iliofemoral stenting in 1 case). A total of 20 patients $(9.7 \%)$ required a permanent pacemaker (PPM) implantation because of severe conduction disorders. Acute kidney injury (AKI) occurred in 21 patients $(10.2 \%)$. The patients who died during this early perioperative period had experienced significantly more AKI $(P=.02)$, bleeding complications $(P=.02)$, and platelet transfusions $(P=.02$, Table E6). Mean procedural time, fluoroscopy time, and amount of contrast media use (49.6 \pm 15.3 minutes vs $67.7 \pm 35.5$ minutes, $11.3 \pm 4.9$ minutes vs $17.8 \pm 8.3$ minutes, and $115.1 \pm 53.3 \mathrm{~mL}$ vs $155.5 \pm 59.9 \mathrm{~mL}$, respectively) were significantly lower among 30-day survivors $(P=.04, .01$, and .02 , respectively).

Mean follow-up was 24.3 months (6.0-65.0), with 196 patients $(95.1 \%)$ followed 12 or more months. One-year overall and cardiovascular mortality rates were $15.5 \%$ and $9.2 \%$, respectively (Table 4). The patients who died during the first postprocedural year had experienced
TABLE 4. One-year outcomes

\begin{tabular}{|c|c|}
\hline & Overall $(n=206)$ \\
\hline Overall mortality & $32(15.5)$ \\
\hline CV mortality & $19(9.2)$ \\
\hline MI & $7(3.4)$ \\
\hline Cerebrovascular event & $8(3.9)$ \\
\hline Stroke & $7(3.4)$ \\
\hline TIA & $1(0.5)$ \\
\hline MACCE (death/MI/stroke) & $40(19.4)$ \\
\hline Life-threatening bleeding & $15(7.3)$ \\
\hline Major vascular complication & $8(3.9)$ \\
\hline New PPM implantation & $21(10.2)$ \\
\hline Relative rehospitalization & $28(13.6)$ \\
\hline $\begin{array}{c}\text { NYHA } \\
\text { I-II } \\
\text { III/IV }\end{array}$ & $\begin{array}{c}141 / 149(94.6) \\
8 / 149(5.4)\end{array}$ \\
\hline $\begin{array}{l}\text { Imaging } \\
\text { Indexed EOA }\left(\mathrm{cm}^{2} / \mathrm{m}^{2}\right) \\
\mathrm{AV} \text { mean gradient }(\mathrm{mm} \mathrm{Hg}) \\
\text { Mild PVL } \\
\text { Moderate to severe PVL } \\
\text { LVEF }(\%) \\
\text { Valve-related dysfunction }\end{array}$ & $\begin{array}{c}1.04 \pm 0.28 \\
10.5 \pm 4.8 \\
8 / 123(6.5) \\
2 / 123(1.6) \\
55.6 \pm 9.4 \\
0(0.0)\end{array}$ \\
\hline $\begin{array}{l}\text { Values are expressed as mean } \pm \mathrm{SD} \\
\text { symptoms or worsening congestive } \mathrm{h} \\
\text { zations. } C V \text {, Cardiovascular; } M I, \mathrm{~m} \\
\text { attack; } M A C C E \text {, major adverse cardia } \\
\text { pacemaker; } N Y H A \text {, New York Heart } \\
\text { aortic valve; } P V L \text {, paravalvular leak; }\end{array}$ & $\begin{array}{l}\text { ations for valve-related } \\
\text { as relative rehospitali- } \\
I A A, \text { transient ischemic } \\
\text { vents; } P P M \text {, permanent } \\
\text { ective orifice area; } A V \text {, } \\
\text { jection fraction. }\end{array}$ \\
\hline
\end{tabular}

significantly more preoperative renal failure $(P=.005)$, 30-day AKI $(P=.001)$, and bleeding complications $(P=.02$, Table E7). During the 1-year follow-up, stroke, transient ischemic attack, and MI occurred in 3.4\%, $0.5 \%$, and $3.4 \%$ of patients, respectively (Table 4 ).

TABLE 5. Thirty-day outcomes: Causes of death

\begin{tabular}{llr}
\hline & Day \\
\hline Patient 1 & Aortic dissection & 0 \\
Patient 2 & Tamponade & 2 \\
Patient 3 & Acute respiratory distress syndrome & 16 \\
Patient 4 & Acute respiratory distress syndrome & 14 \\
\hline Patient 5 & Hemothorax & 11 \\
\hline Patient 6 & Complete atrioventricular block & 1 \\
\hline Patient 7 & Coronary obstruction & 0 \\
\hline Patient 8 & Digestive hemorrhage & 2 \\
\hline Patient 9 & Coronary obstruction & 0 \\
\hline Patient 10 & Multiorgan failure syndrome & 29 \\
\hline Patient 11 & Unknown & 5 \\
\hline
\end{tabular}


Overall survival was $60.7 \%$ (81 deaths; Figures E3 and E4). In the multivariable Cox regression analysis, preoperative renal failure (hazard ratio, 2.82; 95\% confidence interval, 1.73-4.59; $P<.0001$ ) was identified as an independent predictor of overall mortality. We also observed a trend toward the association of PAD with higher mortality (hazard ratio, $1.54 ; 95 \%$ confidence interval, $0.94-2.52 ; P=.09)$ in this series (Table 6).

\section{DISCUSSION}

This report demonstrates that the TAo route had excellent results in a very high-risk population with multiple comorbidities, especially PAD or unsuitable vessel anatomy $(64.1 \%)$ making TF route difficult or impossible ${ }^{9}$ and severe respiratory disease $(38.8 \%)$ or impaired left ventricular ejection fraction, which can be contraindications for the use of TA access. ${ }^{12-14}$

Manubriotomy and cannulation of AA or IA are routinely performed by cardiac surgeons and do not require any additional learning curve, in comparison with TA-TAVI. ${ }^{17}$ Furthermore, as previously reported for TAo-TAVI, ${ }^{17-21}$ our experience of this technique tended to demonstrate that the short distance between the sheath and the aortic annulus enables easier positioning and increased stability of the valve deployment, resulting in a reduction of the fluoroscopy time and the amount of contrast media, compared with TF- or TA-TAVI. ${ }^{23,24}$ All these technical features also may contribute to an optimization of functional outcomes, including reduction of PVL. In our series, no severe leak was observed and respective 30-day and 1-year rates of mild $(6.0 \%$ and $6.5 \%)$ or moderate $(0.0 \%$ and $1.6 \%)$ PVL were very low. In comparison, Bapat and colleagues ${ }^{21}$ have reported $3.4 \%$ of moderate to severe PVL and $19 \%$ of mild PVL, whereas Thourani and colleagues ${ }^{19}$ observed rates of moderate to severe PVL of $6.7 \%$ and $5.6 \%$ with TAo and TA routes, respectively. After evaluation of the outcomes of TF, TA, and SC-TAVI in 3195 patients in the FRANCE 2 registry, Gilard and colleagues ${ }^{10}$ indicated detection of PVL 3 or greater in $18.6 \%, 9 \%$, and $15.2 \%$, respectively. These findings are of importance, as

TABLE 6. Multivariable analysis by the Cox regression proportional hazards model: Prognostic factors of overall mortality

\begin{tabular}{llc}
\hline & HR $(\mathbf{9 5} \%$ CI $)$ & $P$ value \\
\hline Preoperative eGFR $<35 \mathrm{~mL} / \mathrm{min}$ & $2.82(1.73-4.59)$ & $<.0001$ \\
Coronary obstruction & $6.01(1.78-20.36)$ & .004 \\
PAD & $1.54(0.94-2.52)$ & .09 \\
Preoperative conduction disturbances & $1.56(0.87-2.79)$ & .13 \\
Preoperative NYHA class III-IV & $1.41(0.78-2.53)$ & .25 \\
\hline
\end{tabular}

Additional covariables in the multivariable model without near significant contribution to mortality were transcatheter heart valve device, fluoroscopy time, and PVLs. $H R$, Hazard ratio; $C I$, confidence interval; $e G F R$, estimated glomerular filtration rate; $P A D$, peripheral artery disease; NYHA, New York Heart Association. several authors reported postprocedural aortic regurgitation as a strong independent predictor of early and late mortality. ${ }^{25}$

Compared with the AA approach initially used in our experience, the modified technique shifted the access point on the IA, enabling to always maintain the minimal distance of 5 to $7 \mathrm{~cm}$ from the aortic annulus (depending on valve type and size) required for the complete deployment of the device. Despite the remoteness of the insertion site from the native annulus, we observed in this latter group a significant reduction of mean procedural time, fluoroscopy time, and amount of contrast media, along with high procedural success rate and a low, even mild PVL rate (Tables E2, $\mathrm{E} 3$, and E5).

Moreover, the slightest invasiveness of this technique, without opening the pericardium (no pericardial drain), allowed earlier mobilization (from postoperative day 2) and faster patient recovery, and probably participated in the significant reduction of ICU and hospital stays (Table E4).

After the TAVI procedure, a significant decrease in the aortic valve mean gradient and an improvement of the effective orifice area were observed. Likewise, the extent of heart failure symptoms was greatly decreased, with approximately $95 \%$ of patients remaining asymptomatic or having mild symptoms at the 1-year follow-up. All these functional improvements also resulted in a low rate of relative rehospitalizations in the first postprocedural year $(13.6 \%)$, reflecting the beneficial effect of the TAo-TAVI procedure on patients' quality of life. Comparable results have been reported in recent studies. ${ }^{21}$

There were 3 periprocedural deaths $(1.5 \%)$, including 2 intraoperative MIs (1.0\%); the low rates are consistent with those previously reported. ${ }^{17-21}$ One patient required a second valve $(0.5 \%)$ because of the device deployment at a lower level than desired, but there was no conversion to open surgery. These periprocedural results are comparable to data of recent studies on the TAo technique, ranging from $0 \%$ to $2.2 \%$ and $3.3 \%$, respectively, ${ }^{18-21}$ and can be favorably compared with those previously observed for TF-TAVI, ${ }^{1,2,26,27}$ TA-TAVI, ${ }^{19,26,27}$ SC-TAVI, ${ }^{4}$ and transcarotid (TC)-TAVI. ${ }^{6,7}$

Overall 30-day mortality was $5.3 \%$, lower than predicted by logistic euroSCORE II and Society of Thoracic Surgeons Predicted Risk of Mortality score $(16.8 \%$ and $8.9 \%$, respectively). This rate is also similar or lower than reported in the literature for this very high-risk TAVI population, ranging from $4.4 \%$ to $14 \% .{ }^{17-21}$ In comparison, studies regarding TF-TAVI mentioned mortality rates of $6.1 \%$ to $8.5 \%,{ }^{2,10,23}$ whereas published data on TA access are $6.8 \%$ to $14 \%{ }^{8,10,18,19}$ Regarding the results of TC-TAVI in the largest series ever reported (174 patients), Debry and colleagues ${ }^{6}$ pointed out a rate of $7.4 \%$. One-year survival of our patients was encouraging $(85.5 \%)$, partly impaired by noncardiac causes, as demonstrated by the 
low cardiovascular mortality $(9.2 \%)$. These results compare favorably with those of the main studies reporting data of TAo, ${ }^{19,20} \mathrm{TA}^{8,19} \mathrm{TF}^{2,10,23}$ and TC-TAVI. ${ }^{6}$

As reported in previous studies, procedural features and complications mainly affected early mortality, whereas late outcomes were associated with comorbidities, especially in this very high-risk elderly population. ${ }^{28,29}$ Preoperative renal failure was identified as an independent risk factor of overall mortality by multivariable Cox regression analysis. Such an association has been reported. ${ }^{28}$

In the present study, only 3 patients $(1.5 \%)$ experienced 30-day neurologic events; this low rate is consistent with recent reports on TAo-TAVI, ranging from $1.1 \%$ to $2.5 \%,{ }^{19-21}$ and compares favorably with stroke rates of PARTNER B $(6.7 \%)$ and PARTNER A $(5.5 \%) .{ }^{1,2}$ More recently, respective stroke rates observed with the TF, TA, and SC routes were $3.7 \%, 4.4 \%$, and $7 \%$, respectively, in the FRANCE 2 registry $^{10}$ and $2.9 \%, 4.1 \%$, and $9.3 \%$, respectively, in the GARY registry. ${ }^{30}$ In their experience of TC procedures, Debry and colleagues ${ }^{6}$ reported a $30-$ day rate of $5.7 \%$. Late neurologic events occurring after the first perioperative month ( 5 cases in this series) are considered to be influenced by patient- and diseaserelated factors, especially in this very high-risk population (non-TF candidates, $15 \%$ of prior cerebrovascular disease), rather than treatment or intraprocedural variables. ${ }^{31}$ In the study of Van Mieghem and colleagues ${ }^{32}$ using an embolic capture device, aortic, valvular, and thrombotic debris were retrieved in $86 \%$ of patients. Although it is widely believed that the majority of these events are not clinically significant in the short and intermediate terms, their longterm implications may be more impactful, particularly with respect to cognitive and fine motor disabilities. Given the significant impact of strokes on TAVI outcomes, the reduction of their incidence through technique improvements including a reduction of endovascular manipulation represents a major issue. The TAo approach, by avoiding navigation in the aortic arch (mandatory step for the other techniques) together with facilitating valvular crossing and device positioning, potentially decreases the risks of distal embolizations and cerebrovascular events.

There were few life-threatening bleeding and major vascular complications ( $7.3 \%$ and $3.4 \%$, respectively) in our TAo-TAVI series. Once more, this is likely due to the habit of surgeons of aortic cannulation. Of note, lifethreatening bleeding complications were significantly less frequent in the IA group $(P=.03)$, reflecting the safety of this approach. The occurrence of arterial injury when using the TF route is notable, ${ }^{10,23,26,33}$ especially in the case of vasculopathy, a condition found in approximately twothirds of our patients. In the recent OBSERVANT registry, Biancari and colleagues ${ }^{33}$ reported major vascular complication rates of $7.2 \%$ and $1.0 \%$ for the $\mathrm{TF}$ and $\mathrm{TA}$ procedures, respectively. Lardizabal and colleagues ${ }^{18}$ observed lower combined bleeding and vascular events rate in the TAo-TAVI than in the TA approach $(27.0 \%$ vs $46.0 \%$, respectively, $P=.05)$. In TC-TAVI, the rates of vascular complications and combined major and lifethreatening bleeding have been observed to be as high as $11.4 \%$ and $4.5 \%$, respectively. ${ }^{6}$ Packed red blood cell (PRBC) transfusion was required for $36.4 \%$ of our patients, an incidence lower than the $50.7 \%$ and $58.9 \%$ observed by Thourani and colleagues ${ }^{19}$ for the TAo and TA approaches, respectively $(P<.001)$. However, the mean number of transfused PRBC units was $2.6 \pm 1.0$ in our study compared with respective values of $0.5 \pm 0.5$ and $0.6 \pm 0.5$ in their series. ${ }^{19}$ In the OBSERVANT registry, PRBC transfusion rates were $30.4 \%$ and $50.0 \%$ for the TF and TA approaches, respectively, and the mean number of transfused PRBC was $1.1 \pm 1.8$ and $2.4 \pm 3.4$, respectively. ${ }^{33}$ Nonetheless, the interpretation of these results should be cautious because of substantial variability of transfusion policies between institutions and physicians.

In our series, AKI was associated with 30-day mortality in univariable analysis. The 21 patients who experienced AKI $(10.2 \%)$ had received higher amount of contrast media than others $(158.2 \pm 58.1 \mathrm{~mL}$ vs $109.1 \pm 49.8 \mathrm{~mL}$, respectively, $P<.0001)$. Keeping in mind that patients who experienced 30-day death also had significantly higher mean procedural and fluoroscopy times, these findings emphasize that improvement of ease of valve implantation, through the development and refinement of new techniques, is essential to achieve better outcomes.

The low 30-day rate of PPM implantation observed in our study $(9.7 \%$, with only 1 additional case within the 1 -year follow-up) may represent one more indication of the potentially high precision in valve positioning with this technique. Recent studies on TAo-TAVI reported PPM rates of $8.8 \%$ and $14.5 \%$ with balloon-expandable and selfexpanding devices, respectively. ${ }^{20,21}$

\section{Study Limitations}

Although this study provides information about the efficacy and safety of TAo-TAVI in a large population, it carries limitations of noncomparative, nonrandomized analyses of clinical registry data, reporting a single-center experience. The low number of events (ie, 30-day and 1-year deaths and neurologic complications) precluded the use of multivariable analyses for these end points. Otherwise, echocardiographic assessments, especially during the follow-up, were not analyzed in a core echocardiography laboratory, introducing potential inter- and intra-individual variabilities. Finally, the follow-up period was confined to 12 months, without evaluation of longer-term outcomes and complications, which are crucial elements considering the worldwide trend to extend TAVI indications to lowerrisk and younger patients. Further prospective comparative 
studies, including larger patient populations from multicenter series, are required to confirm our results on the TAo approach. Our last comment is relative to the proportion of TAo-TAVI performed in our center, which initially increased (from $19.2 \%$ in 2012 to $22.8 \%$ in 2014), favored by its effectiveness and its safety, but secondarily decreased (from $21.9 \%$ in 2015 to $14.6 \%$ in 2016 , then $9.2 \%$ in 2017), mainly because of the downsizing of the delivery systems, allowing a wide extension of the indications of the TF approach. Nevertheless, the mastery of a safe and effective alternative route remains of fundamental interest in patients with contraindications or a high risk for the $\mathrm{TF}$ technique.

\section{CONCLUSIONS}

We believe that the validity of a TAVI program is conditioned by careful selection of patients and treatment strategies by a multidisciplinary heart team and cautious manipulation of different available approaches, key points to achieve optimal results and avoid risk situations and complications. TAo-TAVI was successfully performed in $98.1 \%$ of cases and was associated with low rates of mortality and adverse events, especially neurologic complications. In our opinion, this technique is an essential tool in the therapeutic armamentarium of a heart team, with excellent results, including in a higher-risk subgroup within the TAVI population. Otherwise, although surgical AVR remains the gold standard technique in low- to intermediate-risk patients, in whom invasiveness is less critical than effectiveness and safety, there is currently a trend toward the extension of the indications of TAVI in lower-risk and younger patients. In this population, further comparative studies of the different TAVI approaches, especially TAo and TF routes, are needed to optimize results and determine the most relevant first-choice strategy.

\section{Conflict of Interest Statement}

B.M. is Medical Proctor for Edwards Lifescience (Irvine, Calif) and Medtronic (Minneapolis, Minn). N.D. is Medical Proctor for Edwards Lifescience, Medtronic, Abbott Vascular (Chicago, Ill), and Boston Scientific (Natick, Mass). T.L. is Medical Proctor for Medtronic. All other authors have nothing to disclose with regard to commercial support.

\section{References}

1. Leon MB, Smith CR, Mack M, Miller DC, Moses JW, Svensson LG, et al. Transcatheter aortic-valve implantation for aortic stenosis in patients who cannot undergo surgery. N Engl J Med. 2010;363:1597-607.

2. Smith CR, Leon MB, Mack MJ, Miller DC, Moses JW, Svensson LG, et al. Transcatheter versus surgical aortic-valve replacement in high-risk patients. N Engl J Med. 2011;364:2187-98.

3. Holmes DR, Mack MJ, Kaul S, Agnihotri A, Alexander KP, Bailey SR, et al. 2012 ACCF/AATS/SCAI/STS expert consensus document on transcatheter aortic valve replacement. J Thorac Cardiovasc Surg. 2012;144:e29-84.
4. Caceres M, Braud R, Roselli EE, Lindroos M, Kupari M, Heikkilä J, et al. The axillary/subclavian artery access route for transcatheter aortic valve replacement: a systematic review of the literature. Ann Thorac Surg. 2012;93:1013-8.

5. Modine T, Lemesle G, Azzaoui R, Sudre A. Aortic valve implantation with the CoreValve ReValving System via left carotid artery access: first case report. J Thorac Cardiovasc Surg. 2010;140:928-9.

6. Debry N, Delhaye C, Azmoun A, Ramadan R, Fradi S, Brenot P, et al. Transcarotid transcatheter aortic valve replacement. JACC Cardiovasc Interv. 2016;9: 2113-20.

7. Kirker EB, Hodson RW, Spinelli KJ, Korngold EC. The carotid artery as a preferred alternative access route for transcatheter aortic valve replacement. Ann Thorac Surg. 2017;104:621-9.

8. Walther T, Kempfert J, Rastan A, Borger MA, Linke A, Ender J, et al. Transapical aortic valve implantation at 3 years. J Thorac Cardiovasc Surg. 2012;143:326-31.

9. Hayashida K, Lefèvre T, Chevalier B, Hovasse T, Romano M, Garot P, et al. Transfemoral aortic valve implantation new criteria to predict vascular complications. JACC Cardiovasc Interv. 2011;4:851-8.

10. Gilard M, Eltchaninoff H, Iung B, Donzeau-Gouge P, Chevreul K, Fajadet J, et al. Registry of transcatheter aortic-valve implantation in high-risk patients. $N$ Engl J Med. 2012;366:1705-15.

11. Wu N, Yan S, Wang X, Lv C, Wang J, Zheng Q, et al. A prospective, single-blind randomised study on the effect of intercostal nerve protection on early postthoracotomy pain relief. Eur J Cardiothorac Surg. 2010;37:840-5.

12. Al-Attar N, Ghodbane W, Himbert D, Rau C, Raffoul R, Messika-Zeitoun D, et al. Unexpected complications of transapical aortic valve implantation. Ann Thorac Surg. 2009;88:90-4.

13. Bleiziffer S, Ruge H, Mazzitelli D, Hutter A, Opitz A, Bauernschmitt R, et al. Survival after transapical and transfemoral aortic valve implantation: talking about two different patient populations. J Thorac Cardiovasc Surg. 2009;138: 1073-80.

14. Wong DR, Ye J, Cheung A, Webb JG, Carere RG, Lichtenstein SV. Technical considerations to avoid pitfalls during transapical aortic valve implantation. $J$ Thorac Cardiovasc Surg. 2010;140:196-202.

15. Bruschi G, de Marco F, Botta L, Cannata A, Oreglia J, Colombo P, et al. Direct aortic access for transcatheter self-expanding aortic bioprosthetic valves implantation. Ann Thorac Surg. 2012;94:497-503.

16. Etienne P-Y, Papadatos S, El Khoury E, Pieters D, Price J, Glineur D. Transaortic transcatheter aortic valve implantation with the Edwards SAPIEN valve: feasibility, technical considerations, and clinical advantages. Ann Thorac Surg. 2011;92:746-8.

17. Hayashida K, Romano M, Lefèvre T, Chevalier B, Farge A, Hovasse T, et al. The transaortic approach for transcatheter aortic valve implantation: a valid alternative to the transapical access in patients with no peripheral vascular option. A single center experience. Eur J Cardiothorac Surg. 2013;44:692-700.

18. Lardizabal JA, O’Neill BP, Desai HV, Macon CJ, Rodriguez AP, Martinez CA, et al. The transaortic approach for transcatheter aortic valve replacement: initial clinical experience in the United States. J Am Coll Cardiol. 2013;61:2341-5.

19. Thourani VH, Jensen HA, Babaliaros V, Suri R, Vemulapalli S, Dai D, et al. Transapical and transaortic transcatheter aortic valve replacement in the United States. Ann Thorac Surg. 2015;100:1718-27.

20. Bruschi G, Branny M, Schiltgen M, Ettori F, Marcheix B, Amrane H, et al. One year outcomes of transcatheter aortic valve implantation using the direct aortic approach. Ann Thorac Surg. 2017;103:1434-40.

21. Bapat V, Frank D, Cocchieri R, Jagielak D, Bonaros N, Aiello M, et al. Transcatheter aortic valve replacement using transaortic access: experience from the multicenter, multinational, prospective ROUTE Registry. JACC Cardiovasc Interv. 2016;9:1815-22.

22. Kappetein AP, Head SJ, Généreux P, Piazza N, van Mieghem NM, Blackstone EH, et al. Updated standardized endpoint definitions for transcatheter aortic valve implantation: the Valve Academic Research Consortium-2 consensus document. J Thorac Cardiovasc Surg. 2013;145:6-23.

23. Van Mieghem NM, Chieffo A, Dumonteil N, Tchetche D, van der Boon RM, Buchanan GL, et al. Trends in outcome after transfemoral transcatheter aortic valve implantation. Am Heart J. 2013;165:183-92.

24. Lefèvre T, Kappetein AP, Wolner E, Nataf P, Thomas M, Schächinger V, et al. One year follow-up of the multi-centre European PARTNER transcatheter heart valve study. Eur Heart J. 2011;32:148-57.

25. Jones BM, Tuzcu EM, Krishnaswamy A, Popovic Z, Mick S, Roselli EE, et al. Prognostic significance of mild aortic regurgitation in predicting mortality after transcatheter aortic valve replacement. J Thorac Cardiovasc Surg. 2016;152: 783-90. 
26. Mack MJ, Brennan JM, Brindis R, Carroll J, Edwards F, Grover F, et al. Outcomes following transcatheter aortic valve replacement in the United States. JAMA. 2013;310:2069-77.

27. Hamm CW, Möllmann H, Holzhey D, Beckmann A, Veit C, Figulla H-R, et al. The German Aortic Valve Registry (GARY): in-hospital outcome. Eur Heart J. 2014;35:1588-98.

28. Holmes DR, Brennan JM, Rumsfeld JS, Dai D, O'Brien SM, Vemulapalli S, et al. Clinical outcomes at 1 year following transcatheter aortic valve replacement. JAMA. 2015;313:1019-28.

29. Gaudiani V, Deeb GM, Popma JJ, Adams DH, Gleason TG, Conte JV, et al. Causes of death from the randomized CoreValve US Pivotal High-Risk Trial. $J$ Thorac Cardiovasc Surg. 2017;153:1293-301.e1.

30. Werner N, Zeymer U, Schneider S, Bauer T, Gerckens U, Linke A, et al. Incidence and clinical impact of stroke complicating transcatheter aortic valve implantation: results from the German TAVI Registry. Catheter Cardiovasc Interv. 2016;88:644-53.
31. Miller DC, Blackstone EH, Mack MJ, Svensson LG, Kodali SK, Kapadia S, et al Transcatheter (TAVR) versus surgical (AVR) aortic valve replacement: occurrence, hazard, risk factors, and consequences of neurologic events in the PARTNER trial. J Thorac Cardiovasc Surg. 2012;143:832-43.e13.

32. Van Mieghem NM, El Faquir N, Rahhab Z, Rodríguez-Olivares R, Wilschut J, Ouhlous $\mathrm{M}$, et al. Incidence and predictors of debris embolizing to the brain during transcatheter aortic valve implantation. JACC Cardiovasc Interv. 2015; 8:718-24.

33. Biancari F, Rosato S, D’Errigo P, Ranucci M, Onorati F, Barbanti M, et al. Immediate and intermediate outcome after transapical versus transfemoral transcatheter aortic valve replacement. Am J Cardiol. 2016;117:245-51

Key Words: aortic route, innominate route, transcatheter aortic valve implantation 


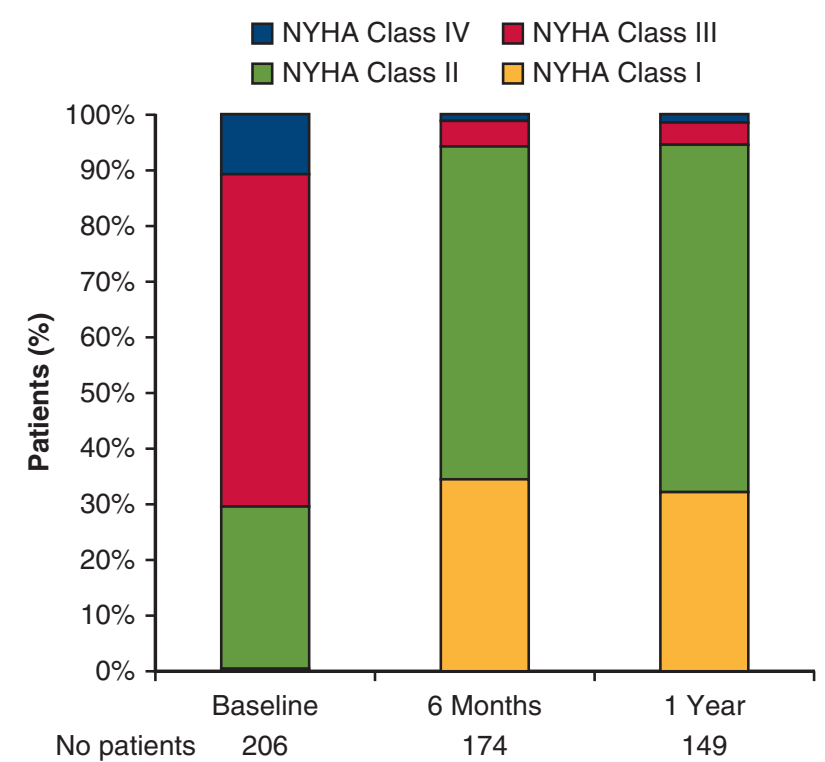

FIGURE E1. NYHA functional status. Proportions of patients in each NYHA functional class based on their symptoms. Percentages expressed are related to the number of patients alive for whom status was known at each time point. NYHA, New York Heart Association.

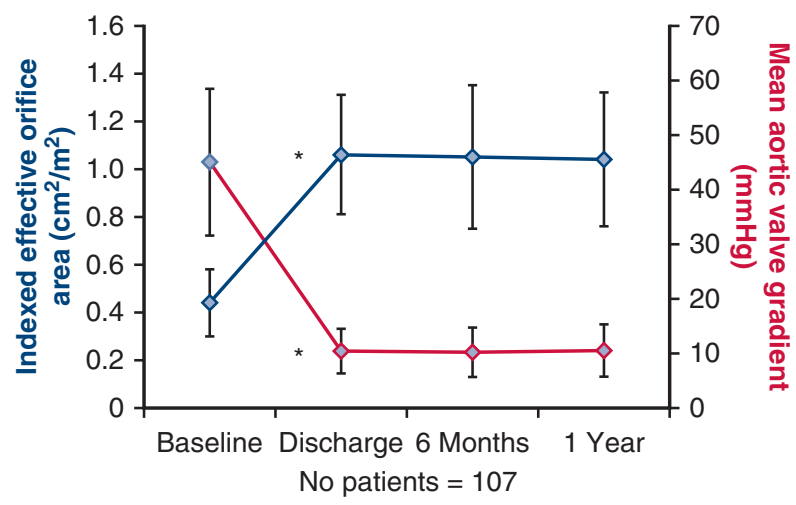

FIGURE E2. Valve hemodynamics during the follow-up period. Mean transvalvular gradient and indexed effective orifice area over time. Baseline versus follow-up $* P<.0001$. No significant changes in valve hemodynamics were observed during the follow-up period. Analyses of variance were done with Kruskal-Wallis test for patients $(n=107)$ in whom the data of the echocardiographic assessment at each time point were available. 


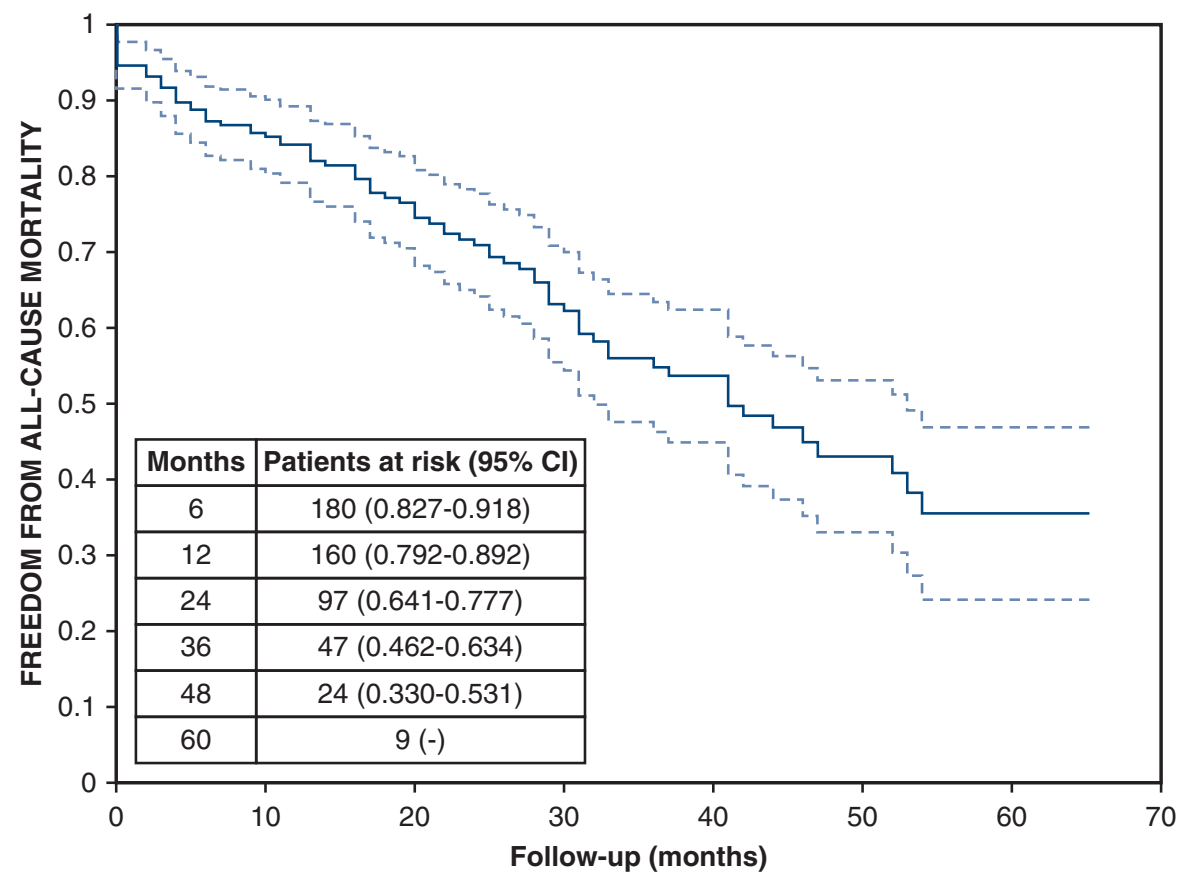

FIGURE E3. Kaplan-Meier analysis of freedom from all-cause mortality. $C I$, Confidence interval.

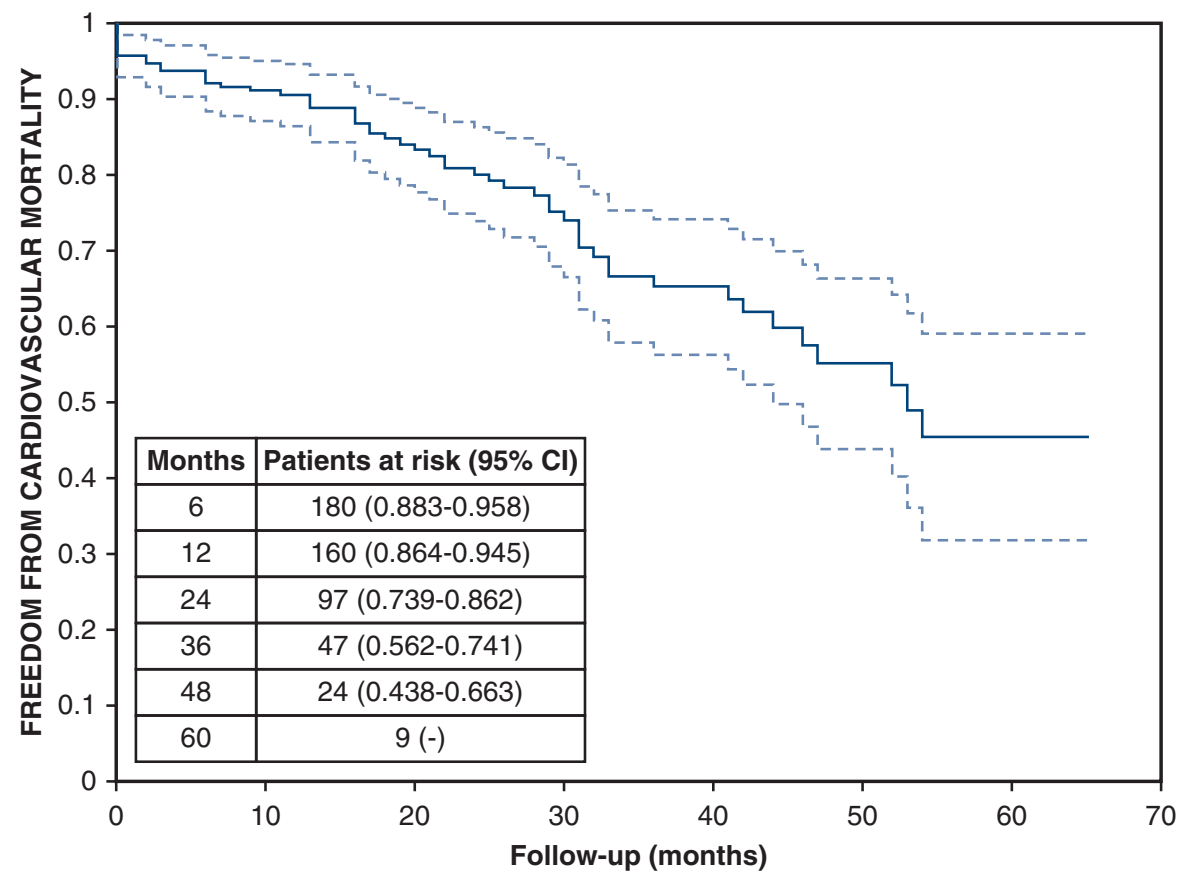

FIGURE E4. Kaplan-Meier analysis of freedom from cardiovascular mortality. Deaths from unknown cause were assumed to be of cardiovascular cause. CI, Confidence interval. 
TABLE E1. Step-by-step technique

\begin{tabular}{|c|c|}
\hline Step 1 & $\begin{array}{l}\text { Insertion of a femoral arterial sheath }(6 \mathrm{~F}) \text {, through a perclosure device } \\
\text { Positioning of a pigtail catheter into the aortic root (noncoronary sinus) }\end{array}$ \\
\hline Step 2 & Insertion of a transvenous pacing wire in the right ventricle through the femoral vein \\
\hline Step 3 & Reverse J-shaped manubriotomy down to the second right intercostal space \\
\hline Step 4 & Exposure of the distal AA/IA \\
\hline Step 5 & Selection of a safe entry site: preoperative assessment by CT scan and intraoperative evaluation by direct palpation \\
\hline Step 6 & Two pledgeted purse string sutures \\
\hline Step 7 & Heparin IV injection (100 UI/kg) to provide an activated clotting time $\geq 300 \mathrm{~s}$ \\
\hline Step 8 & Direct needle puncture, introduction of a J-shaped 0.035 -inch soft guide wire and positioning of a $7 \mathrm{~F}$ short sheath in the AA \\
\hline Step 9 & Native aortic valve retrograde crossing using a JR4 $(6 \mathrm{~F})$ catheter on a 0.035 -inch straight guide wire \\
\hline Step 10 & Hemodynamic assessment of the transvalvular gradients \\
\hline Step 11 & Exchange of the guide wire for a preshaped superstiff guide wire positioned in the left ventricle \\
\hline Step 12 & Exchange of the $7 \mathrm{~F}$ sheath for the device sheath \\
\hline Step 13 & Introduction of the delivery system \\
\hline Step 14 & Careful positioning and deployment of the device, under angiographic guidance \\
\hline Step 15 & Angiographic assessment: device deployment, patency of coronary arteries, PVLs \\
\hline Step 16 & Removal of the delivery system \\
\hline Step 17 & Removal of guidewire, catheter, and sheath; knotting of purse string sutures \\
\hline Step 18 & Closure of incision in anatomic layers \\
\hline Step 19 & $\begin{array}{l}\text { Removal of pigtail and percutaneous closure (prepositioned device) } \\
\text { Removal of pacing wire and external compressing }\end{array}$ \\
\hline
\end{tabular}

$A A$, Ascending aorta; $I A$, innominate artery; $C T$, computed tomography; $I V$, intravenous; $P V L$, paravalvular leak. 
TABLE E2. Baseline characteristics

\begin{tabular}{|c|c|c|c|c|}
\hline & Overall $(n=206)$ & $\mathbf{A A}(\mathbf{n}=56)$ & IA $(n=150)$ & $P$ value \\
\hline Age (y) & $83.9 \pm 6.7$ & $84.5 \pm 6.4$ & $83.6 \pm 6.8$ & .27 \\
\hline Female gender & $120(58.3)$ & $32(57.1)$ & $88(58.7)$ & .88 \\
\hline Diabetes mellitus & $65(31.6)$ & $12(21.4)$ & $53(35.3)$ & .07 \\
\hline \multicolumn{5}{|l|}{ NYHA class } \\
\hline I-II & $61(29.6)$ & $7(12.5)$ & $54(36.0)$ & .001 \\
\hline III-IV & $145(70.4)$ & $49(87.5)$ & $96(64.0)$ & \\
\hline Pulmonary edema & $103(50.0)$ & $25(44.6)$ & $78(52.0)$ & .43 \\
\hline Angina pectoris CCS class III-IV & $42(20.4)$ & $12(21.4)$ & $30(20.0)$ & .85 \\
\hline Prior relative hospitalization & $150(72.8)$ & $48(85.7)$ & $102(68.0)$ & .01 \\
\hline \multicolumn{5}{|l|}{ Cardiac comorbidity } \\
\hline Coronary artery disease & $130(63.1)$ & $26(46.4)$ & $104(69.3)$ & .003 \\
\hline Previous MI & $31(15.0)$ & $9(16.1)$ & $22(14.7)$ & .83 \\
\hline Previous PCI & $95(46.1)$ & $20(35.7)$ & $75(50.0)$ & .08 \\
\hline Previous CABG & $20(9.7)$ & $1(1.8)$ & $19(12.7)$ & .02 \\
\hline Previous AVR & $5(2.4)$ & $0(0.0)$ & $5(3.3)$ & .33 \\
\hline Other previous cardiac surgery & $3(1.5)$ & $0(0.0)$ & $3(2.0)$ & .29 \\
\hline Atrial fibrillation & $64(31.1)$ & $10(17.9)$ & $54(36.0)$ & .02 \\
\hline Previous pacemaker implantation & $29(14.1)$ & $8(14.3)$ & $21(14.0)$ & 1 \\
\hline \multicolumn{5}{|l|}{ Extracardiac comorbidity } \\
\hline Cerebrovascular disease & $31(15.0)$ & $12(21.4)$ & 19 (12.7) & .13 \\
\hline $\mathrm{PAD}$ & $132(64.1)$ & $30(53.6)$ & $102(68.0)$ & .07 \\
\hline Severe COPD & $80(38.8)$ & $26(46.4)$ & $54(36.0)$ & .2 \\
\hline Renal failure (eGFR $<35 \mathrm{~mL} / \mathrm{min}$ ) & $47(22.8)$ & $8(14.3)$ & $39(26.0)$ & .09 \\
\hline Liver cirrhosis & $2(0.9)$ & $0(0.0)$ & $2(1.3)$ & .39 \\
\hline \multicolumn{5}{|l|}{ Surgical risk } \\
\hline Logistic euroSCORE II (\%) & $16.8 \pm 10.8$ & $19.2 \pm 9.8$ & $15.8 \pm 11.04$ & .004 \\
\hline STS PROM score $(\%)$ & $8.9 \pm 5.4$ & $8.8 \pm 4.1$ & $6.4 \pm 2.8$ & .005 \\
\hline \multicolumn{5}{|l|}{ Unfavorable anatomic features } \\
\hline Porcelain aorta & $8(3.9)$ & $1(1.8)$ & $7(4.7)$ & .69 \\
\hline Mediastinal radiation therapy & $14(6.8)$ & $4(7.1)$ & $10(6.7)$ & 1 \\
\hline ITA or other conduit crossing midline & $18(8.7)$ & $1(1.8)$ & $17(11.3)$ & .03 \\
\hline \multicolumn{5}{|l|}{ Imaging } \\
\hline Indexed EOA $\left(\mathrm{cm}^{2} / \mathrm{m}^{2}\right)$ & $0.44 \pm 0.14$ & $0.44 \pm 0.11$ & $0.44 \pm 0.15$ & .99 \\
\hline AV mean gradient $(\mathrm{mm} \mathrm{Hg})$ & $44.3 \pm 14.8$ & $43.2 \pm 13.1$ & $44.7 \pm 15.5$ & .65 \\
\hline $\operatorname{LVEF}(\%)$ & $52.7 \pm 14.4$ & $55.6 \pm 14.1$ & $51.6 \pm 14.4$ & .1 \\
\hline Moderate or severe MR & $5 / 190(2.6)$ & $0(0.0)$ & $5 / 136(3.7)$ & .32 \\
\hline Previous aortic valvuloplasty & $71(34.5)$ & $17(30.4)$ & $54(36)$ & .5 \\
\hline
\end{tabular}

Values are expressed as mean $\pm \mathrm{SD}$ or n (\%). AA, Ascending aorta; IA, innominate artery; NYHA, New York Heart Association; CCS, Canadian Cardiovascular Society; $M I$, myocardial infarction; $P C I$, percutaneous coronary intervention; $C A B G$, coronary artery bypass grafting; $A V R$, aortic valve replacement; $P A D$, peripheral artery disease; COPD, chronic obstructive pulmonary disease; eGFR, estimated glomerular filtration rate; euroSCORE, European System for Cardiac Risk Evaluation; STS PROM, Society of Thoracic Surgeons Predicted Risk of Mortality; ITA, internal thoracic artery; $E O A$, effective orifice area; $A V$, aortic valve; $L V E F$, left ventricular ejection fraction; $M R$, mitral regurgitation. 
TABLE E3. Procedural outcomes

\begin{tabular}{|c|c|c|c|c|}
\hline & Overall $(n=206)$ & $\mathrm{AA}(\mathrm{n}=56)$ & IA $(n=150)$ & $P$ value \\
\hline Access & & & & - \\
\hline AA route & $56(27.2)$ & $56(100)$ & $0(0.0)$ & \\
\hline IA route & $150(72.8)$ & $0(0.0)$ & $150(100)$ & \\
\hline Procedural time (min) & $50.6 \pm 12.3$ & $60.4 \pm 18.4$ & $46.9 \pm 15.4$ & .09 \\
\hline Fluoroscopy time (min) & $11.6 \pm 3.8$ & $12.8 \pm 5.1$ & $11.3 \pm 5.3$ & .03 \\
\hline Contrast media used $(\mathrm{mL})$ & $117.3 \pm 40.5$ & $143.5 \pm 64.7$ & $107.6 \pm 46.6$ & $<.0001$ \\
\hline Valve implanted & & & & $<.0001$ \\
\hline SAPIEN XT & $56(27.2)$ & $34(60.7)$ & $22(14.7)$ & \\
\hline SAPIEN 3 & $67(32.5)$ & $0(0.0)$ & $67(44.7)$ & \\
\hline CoreValve & $73(35.4)$ & $22(39.3)$ & $51(34)$ & \\
\hline EvolutR & $10(4.9)$ & $0(0.0)$ & $10(6.6)$ & \\
\hline Valve size $(\mathrm{mm})$ & & & & .33 \\
\hline 23 & $51(24.8)$ & $8(14.3)$ & $43(28.7)$ & \\
\hline 26 & $86(41.7)$ & $30(53.6)$ & $56(37.3)$ & \\
\hline$\geq 29$ & $69(33.5)$ & $18(32.1)$ & $51(34)$ & \\
\hline VARC-2 procedural success & $202(98.1)$ & $54(96.4)$ & $148(98.7)$ & 1 \\
\hline Second valve & $1(0.5)$ & $1(1.8)$ & $0(0.0)$ & \\
\hline Coronary obstruction & $4(1.9)$ & $1(1.8)$ & $3(2.0)$ & \\
\hline Conversion to surgery & $0(0.0)$ & $0(0.0)$ & $0(0.0)$ & \\
\hline Periprocedural death & $3(1.5)$ & $1(1.8)$ & $2(1.3)$ & \\
\hline PVL & & & & .19 \\
\hline Mild & $13(6.3)$ & $1(1.8)$ & $12(8.0)$ & \\
\hline Moderate to severe & $0(0.0)$ & $0(0.0)$ & $0(0.0)$ & \\
\hline \multicolumn{5}{|l|}{ Transfusions } \\
\hline PRBC use & $75(36.4)$ & $23(41.1)$ & $52(34.7)$ & .42 \\
\hline PRBC units transfused & $2.6 \pm 1.0$ & $3.5 \pm 2.1$ & $2.3 \pm 0.9$ & .02 \\
\hline Platelet use & $6(2.9)$ & $5(8.9)$ & $1(0.7)$ & .006 \\
\hline Platelet units transfused & $6 \pm 1.6$ & $5.5 \pm 2.1$ & 8 & .47 \\
\hline
\end{tabular}

Values are expressed as mean $\pm \mathrm{SD}$ or $\mathrm{n}(\%)$. AA, Ascending aorta; IA, innominate artery; VARC-2, Valve Academic Research Consortium-2; PVL, paravalvular leak; $P R B C$, packed red blood cells. 
TABLE E4. Thirty-day outcomes

\begin{tabular}{|c|c|c|c|c|}
\hline & Overall $(n=206)$ & $\mathbf{A A}(\mathbf{n}=56)$ & IA $(n=150)$ & $P$ value \\
\hline ICU stay (d) & $2.5 \pm 1.7$ & $3.8 \pm 4.2$ & $2.0 \pm 2.1$ & $<.0001$ \\
\hline Hospital stay (d) & $8.1 \pm 2.6$ & $9.8 \pm 4.6$ & $7.6 \pm 3.4$ & $<.0001$ \\
\hline Overall mortality & $11(5.3)$ & $5(8.9)$ & $6(4.0)$ & .17 \\
\hline CV mortality & $9(4.4)$ & $3(5.4)$ & $6(4.0)$ & .7 \\
\hline MI & $2(1.0)$ & $0(0.0)$ & $2(1.3)$ & 1 \\
\hline Cerebrovascular event & $3(1.5)$ & $1(1.8)$ & $2(1.3)$ & 1 \\
\hline Stroke & $2(1.0)$ & $1(1.8)$ & $1(0.7)$ & \\
\hline TIA & $1(0.5)$ & $0(0.0)$ & $1(0.7)$ & \\
\hline MACCE (death/MI/stroke) & $13(6.3)$ & $6(10.7)$ & $7(4.7)$ & .12 \\
\hline Life-threatening bleeding & $15(7.3)$ & $8(14.3)$ & $7(4.7)$ & .03 \\
\hline Major vascular complication & $8(3.9)$ & $3(5.4)$ & $5(3.3)$ & .45 \\
\hline AKI (stage 2 or 3 ) & $5(2.4)$ & $2(3.6)$ & $3(2.0)$ & .61 \\
\hline New PPM implantation & $20(9.7)$ & $3(5.4)$ & $17(11.3)$ & .29 \\
\hline \multicolumn{5}{|l|}{ Imaging } \\
\hline Indexed EOA $\left(\mathrm{cm}^{2} / \mathrm{m}^{2}\right)$ & $1.06 \pm 0.21$ & $1.06 \pm 0.22$ & $1.06 \pm 0.26$ & .82 \\
\hline AV mean gradient (mm Hg) & $10.5 \pm 3.2$ & $9.6 \pm 4.2$ & $10.9 \pm 3.9$ & .03 \\
\hline Mild PVL & $12 / 200(6.0)$ & $4 / 53(7.5)$ & $8 / 147(5.4)$ & .52 \\
\hline Moderate to severe PVL & $0(0.0)$ & $0(0.0)$ & $0(0.0)$ & \\
\hline $\operatorname{LVEF}(\%)$ & $52.5 \pm 9.7$ & $55.9 \pm 11.3$ & $51.3 \pm 12.9$ & .05 \\
\hline Valve-related dysfunction & $0(0.0)$ & $0(0.0)$ & $0(0.0)$ & \\
\hline
\end{tabular}

Values are expressed as mean $\pm \mathrm{SD}$ or n (\%). $A A$, Ascending aorta; $I A$, innominate artery; $I C U$, intensive care unit; $C V$, cardiovascular; $M I$, myocardial infarction; $T I A$, transient ischemic attack; $M A C C E$, major adverse cardiac and cerebrovascular events; $A K I$, acute kidney injury (according to the AKI Network criteria); $P P M$, permanent pacemaker; $E O A$, effective orifice area; $A V$, aortic valve; $P V L$, paravalvular leak; $L V E F$, left ventricular ejection fraction. 
TABLE E5. One-year outcomes

\begin{tabular}{|c|c|c|c|c|}
\hline & Overall $(n=206)$ & $\mathbf{A A}(\mathbf{n}=56)$ & IA $(n=150)$ & $P$ value \\
\hline Overall mortality & $32(15.5)$ & $10(17.9)$ & $22(14.7)$ & .6 \\
\hline CV mortality & $19(9.2)$ & $5(8.9)$ & $14(9.3)$ & 1 \\
\hline MI & $7(3.4)$ & $2(3.6)$ & $5(3.3)$ & 1 \\
\hline Cerebrovascular event & $8(3.9)$ & $1(1.8)$ & $7(4.7)$ & .7 \\
\hline Stroke & $7(3.4)$ & $1(1.8)$ & $6(4.0)$ & .7 \\
\hline TIA & $1(0.5)$ & $0(0.0)$ & $1(0.7)$ & 1 \\
\hline MACCE (death/MI/stroke) & $40(19.4)$ & $11(19.6)$ & $29(19.3)$ & 1 \\
\hline Life-threatening bleeding & $15(7.3)$ & $8(14.3)$ & $7(4.7)$ & .03 \\
\hline Major vascular complication & $8(3.9)$ & $3(5.4)$ & $5(3.3)$ & .45 \\
\hline New PPM implantation & $21(10.2)$ & $4(7.1)$ & $17(11.3)$ & .45 \\
\hline Relative rehospitalization & $28(13.6)$ & $10(17.9)$ & $18(12.0)$ & .36 \\
\hline $\begin{array}{c}\text { NYHA } \\
\text { I-II } \\
\text { III/IV }\end{array}$ & $\begin{array}{c}141 / 149(94.6) \\
8 / 149(5.4)\end{array}$ & $\begin{array}{c}38 / 42(90.5) \\
4 / 42(9.5)\end{array}$ & $\begin{array}{c}103 / 107(96.3) \\
4 / 107(3.7)\end{array}$ & .22 \\
\hline \multicolumn{5}{|l|}{ Imaging } \\
\hline Indexed EOA $\left(\mathrm{cm}^{2} / \mathrm{m}^{2}\right)$ & $1.04 \pm 0.28$ & $1.1 \pm 0.3$ & $1.0 \pm 0.3$ & .61 \\
\hline $\mathrm{AV}$ mean gradient $(\mathrm{mm} \mathrm{Hg})$ & $10.5 \pm 4.8$ & $8.7 \pm 3.2$ & $11.1 \pm 5.1$ & .008 \\
\hline Mild PVL & $8 / 123(6.5)$ & $4 / 40(10.0)$ & $4 / 83(4.8)$ & .44 \\
\hline Moderate to severe PVL & 2/123 (1.6) & $0 / 40(0.0)$ & $2 / 83(2.4)$ & 1 \\
\hline $\operatorname{LVEF}(\%)$ & $55.6 \pm 9.4$ & $55.6 \pm 14.7$ & $55.6 \pm 11$ & .44 \\
\hline Valve-related dysfunction & $0(0.0)$ & $0(0.0)$ & $0(0.0)$ & - \\
\hline
\end{tabular}

Values are expressed as mean \pm SD or $\mathrm{n}(\%)$. Hospitalizations for valve-related symptoms or worsening congestive heart failure are reported as relative rehospitalizations. $A A$, Ascending aorta; $I A$, innominate artery; $C V$, cardiovascular; $M I$, myocardial infarction; $T I A$, transient ischemic attack; $M A C C E$, major adverse cardiac and cerebrovascular events; $P P M$, permanent pacemaker; $N Y H A$, New York Heart Association; $E O A$, effective orifice area; $A V$, aortic valve; $P V L$, paravalvular leak; $L V E F$, left ventricular ejection fraction.

TABLE E6. Univariable analysis of 30-day overall mortality (only variables with a $P$ value $\leq .2$ are reported)

\begin{tabular}{lccc}
\hline \multicolumn{1}{c}{ Variable } & $\begin{array}{c}\text { Survival } \\
(\mathbf{n}=\mathbf{1 9 5})\end{array}$ & $\begin{array}{c}\text { Death } \\
(\mathbf{n}=\mathbf{1 1})\end{array}$ & $\boldsymbol{P}$ value \\
\hline COPD & $73(37.4)$ & $7(63.6)$ & .11 \\
Pericardium opening & $31(15.9)$ & $4(36.4)$ & .09 \\
\hline IA access & $144(73.8)$ & $6(54.5)$ & .17 \\
\hline AA access & $51(26.2)$ & $5(45.5)$ & .17 \\
\hline Procedural time (min) & $49.6 \pm 15.3$ & $67.7 \pm 35.5$ & .04 \\
Fluoroscopy time (min) & $11.3 \pm 4.9$ & $17.8 \pm 8.3$ & .01 \\
\hline Contrast media used (mL) & $115.1 \pm 53.3$ & $155.5 \pm 59.9$ & .02 \\
AKI & $17(8.7)$ & $4(36.4)$ & .02 \\
\hline Bleeding & $29(14.9)$ & $5(45.5)$ & .02 \\
Platelet use & $4(2.1)$ & $2(18.2)$ & .03 \\
\hline
\end{tabular}

Values are expressed as mean $\pm \mathrm{SD}$ or $\mathrm{n}(\%) . C O P D$, Chronic obstructive pulmonary disease; $I A$, innominate artery; $A A$, ascending aorta; $A K I$, acute kidney injury.
TABLE E7. Univariable analysis of 1-year overall mortality (only variables with a $P$ value $\leq .2$ are reported)

\begin{tabular}{lccc}
\hline & $\begin{array}{c}\text { Survival } \\
(\mathbf{n}=\mathbf{1 7 4})\end{array}$ & $\begin{array}{c}\text { Death } \\
(\mathbf{n}=\mathbf{3 2})\end{array}$ & $\boldsymbol{P}$ value \\
\hline Diabetes mellitus & $59(33.9)$ & $6(18.8)$ & .1 \\
Preoperative conduction disturbances & $24(13.8)$ & $8(25.0)$ & .09 \\
PAD & $107(61.5)$ & $25(78.1)$ & .08 \\
Preoperative eGFR $<35 \mathrm{~mL} / \mathrm{min}$ & $33(18.9)$ & $14(43.8)$ & .005 \\
AKI & $12(6.9)$ & $9(28.1)$ & .001 \\
Life-threatening bleeding & $9(5.2)$ & $6(18.8)$ & .02 \\
PRBC use & $59(33.9)$ & $16(50.0)$ & .1 \\
Vascular complications & $7(4.0)$ & $4(12.5)$ & .07 \\
\hline
\end{tabular}

Values are expressed as $\mathrm{n}(\%) . P A D$, Peripheral artery disease; $e G F R$, estimated glomerular filtration rate; $A K I$, acute kidney injury; $P R B C$, packed red blood cells. 